\title{
Non-invasive blood pressure monitoring in an anaesthetised calf - a case report
}

\author{
J.S. Souljai' ${ }^{1}$, S. Sooryadas ${ }^{2}$, P.T. Dinesh ${ }^{3}$, \\ George Chandy² and O. K. Sindhu ${ }^{3}$ \\ College of Veterinary and Animal Sciences, Pookode, Wayanad, 673576. \\ Kerala Veterinary and Animal Sciences University, India.
}

Citation: Souljai, J. S., Sooryadas, S., Dinesh, P.T., George, C. and Sindhu, O. K. 2021. Non-invasive blood pressure monitoring in an anaesthetised calf - a case report. J. Vet. Anim. Sci. 52(2): 204-207. DOI: https://doi.org/10.51966/jvas.2021.52.2.204-207

Received: 29.12.2020

Accepted: 01.02.2021

Published:01.06.2021

\begin{abstract}
A six month old cross bred calf was presented with a swelling on lateral abdomen and diagnosed with lateral abdominal hernia, which underwent herniorrhaphy under general anaesthesia formed the subject of the study. The animal was administered with meloxicam @ $0.5 \mathrm{mg} / \mathrm{kg}$ body weight intravenously for pre-emptive analgesia. Thirty minutes later, xylazine @ $0.02 \mathrm{mg} / \mathrm{kg}$ and butorphanol @ $0.05 \mathrm{mg} / \mathrm{kg}$, were administered intravenously. Upon sedation, the animal was administered with a loading dose of lignocaine @ $1 \mathrm{mg} / \mathrm{kg}$ body weight intravenously. Immediately following the loading dose of lignocaine, anaesthesia was induced using guaiphenesin @ $50 \mathrm{mg} / \mathrm{kg}$ and ketamine @ 2mg/kg intravenously. Following induction, anaesthesia was maintained using the prepared guaiphenesin-ketamine-lignocaine-butorphanol anaesthetic mixture as continuous rate infusion @ $3 \mathrm{ml} / \mathrm{kg} / \mathrm{hr}$. Indirect and direct blood pressure measurements were monitored and recorded. The non-invasive blood pressure values for systolic, diastolic and mean blood pressures did not differ significantly $(p>0.05)$ from those monitored invasively.
\end{abstract}

Keywords: Anaesthesia, non-invasive blood pressure, invasive blood pressure, calf, intravenous anaesthesia

Every anaesthetic drug causes changes in the homeostasis of the animal hence warranting constant monitoring of anaesthetised patient. Of the many parameters measured, blood pressure is the key to understand patients' cardiovascular status. Hypotension, a common

*Part of MVSc. Thesis submitted by the first author to Kerala Veterinary and Animals Sciences University, Pookode, Wayanad, Kerala

1. MVSc.Scholar, Corresponding author, E-mail:drsouljaijs@gmail.com, Phone: 6282621919

2. Assistant Professor, Dept. of Veterinary Surgery and Radiology

3. Assistant Professor and Head, Dept. of Veterinary Surgery and Radiology

4. Assistant Professor, Dept. of Clinical Medicine, Ethics and Jurisprudence

Copyright: @ 2021 J.S. Souljai et al. This is an open access article distributed under the terms of the Creative Commons Attribution 4.0 International License (http://creativecommons.org/licenses/by/4.0/), which permits unrestricted use, distribution, and reproduction in any medium, provided the original author and source are credited. 
drawback of most anaesthetic drug, if left unmonitored can lead to detrimental effects for the patient during and after surgery. Arterial blood pressure can be measured by two techniques - invasive (direct) and non-invasive (indirect) methods. Invasive blood pressure (IBP) monitoring is reported to be the most accurate method for blood pressure monitoring (Afshar et al, 2005). High cost of equipment, requirement of technical skill in catheterising arteries and calibrating transducers are the constraints involved in usage of IBP in field conditions. Non-invasive blood pressure (NIBP) monitoring is an alternative to invasive blood pressure monitoring. It is economical and requires minimal technical knowledge with easy applicability in field practice. But the debate on reliability of blood pressure values monitored non-invasively keeps away the field practitioner from depending on noninvasive blood pressure monitoring for routine practice. The present study plays on record a comparative evaluation of blood pressures monitored non-invasively to that monitored invasively by arterial catheterisation.

A six month old cross bred calf weighing $48.5 \mathrm{~kg}$, presented to the Teaching Veterinary Clinical Complex, Pookode with a swelling on lateral abdomen and diagnosed with lateral abdominal hernia, classified as ASA class I which underwent herniorrhaphy under general anaesthesia formed the subject of the study. Following fasting, the animal was administered with meloxicam @ 0.5 mg/ $\mathrm{kg}$ body weight intravenously for pre-emptive analgesia. Thirty minutes later, xylazine @ 0.02 $\mathrm{mg} / \mathrm{kg}$ and butorphanol @ $0.05 \mathrm{mg} / \mathrm{kg}$, were administered intravenously. Upon sedation, the animal was administered with a loading dose of lignocaine @ $1 \mathrm{mg} / \mathrm{kg}$ body weight intravenously. Immediately following the loading dose of lignocaine, guaiphenesin @ 50 mg/kg and ketamine @ 2mg/kg intravenously were used for induction of anaesthesia. Intubation using suitable size endotracheal tube was carried out and then connected to a fresh oxygen supply using a Boyle's apparatus. Following induction, anaesthesia was maintained using the prepared guaiphenesin-ketamine-lignocainebutorphanol anaesthetic mixture as continuous rate infusion @ $3 \mathrm{ml} / \mathrm{kg} / \mathrm{hr}$ so as to deliver guaiphenesin @ 150 mg/kg/hr, ketamine @ $6 \mathrm{mg} / \mathrm{kg} / \mathrm{hr}$, lignocaine @ $3 \mathrm{mg} / \mathrm{kg} / \mathrm{hr}$ and butorphanol @ $21 \mathrm{mcg} / \mathrm{kg} / \mathrm{hr}$. Indirect blood pressure measurements were made using an NIBP cuff of width approximately 40 percent of the circumference of the base of the tail, wrapped around the tail base and connected to the multipara patient monitor for monitoring the non-invasive blood pressure throughout the anaesthesia. The NIBP cuff was applied over the coccygeal artery. A 22G catheter was placed into the auricular artery, following aseptic preparation of the site and was then secured using tape. The catheter was then connected to a blood pressure transducer (disposable) through a heparin saline packed tubing (Fig. 1). Care was taken to place the transducer at the same level as that of the heart. The apparatus, with respect to the local atmospheric pressure, was then zeroed. NIBP and IBP were monitored and recorded at every 15 minute till recovery.

The non-invasive mean blood pressure values after induction and every fifteen minutes thereafter till recovery ranged from 78 to $117 \mathrm{mmHg}$ with a mean $\pm \mathrm{SE}$ of $93.50 \pm 5.86$ $\mathrm{mmHg}$, while the invasive mean blood pressure values varied from 93 to $108 \mathrm{mmHg}$ with a mean $\pm \mathrm{SE}$ of $102.83 \pm 2.79 \mathrm{mmHg}$. The non-invasive diastolic blood pressure values after induction and every fifteen minutes thereafter till recovery ranged from 65 to $91 \mathrm{mmHg}$ with a mean $\pm \mathrm{SE}$ of $74.3 \pm 4.43 \mathrm{mmHg}$, while the invasive diastolic blood pressure values varied from 79 to 94 $\mathrm{mmHg}$ with a mean $\pm \mathrm{SE}$ of $85.66 \pm 2.53 \mathrm{mmHg}$. The non-invasive systolic blood pressure values after induction and every fifteen minutes thereafter till recovery ranged from 104 to 151 $\mathrm{mmHg}$ with a mean $\pm \mathrm{SE}$ of $124.6 \pm 7.33 \mathrm{mmHg}$, while the invasive systolic blood pressure values varied from 115 to $130 \mathrm{mmHg}$ with a mean $\pm \mathrm{SE}$ of $123.5 \pm 2.70 \mathrm{mmHg}$. The non-invasive blood pressure values for systolic, diastolic and mean blood pressures - did not differ significantly $(p>0.05)$ from those monitored invasively. The co-efficient of variation for the values studied were less than 20 per cent, suggesting that the experiment was reliable.

The values obtained for invasive and non-invasive blood pressure are illustrated in Table 1. 
Table 1: NIBP and IBP values obtained during anaesthesia

\begin{tabular}{|c|c|c|c|c|c|c|}
\hline \multirow{2}{*}{ Time } & \multicolumn{3}{|c|}{$\begin{array}{c}\text { Non-invasive blood pressure } \\
\text { monitoring }\end{array}$} & \multicolumn{3}{c|}{$\begin{array}{c}\text { Invasive blood pressure } \\
\text { monitoring }\end{array}$} \\
\cline { 2 - 7 } & Systolic & Diastolic & Mean & Systolic & Diastolic & Mean \\
\hline After induction & 151 & 91 & 117 & 122 & 82 & 102 \\
\hline 15 minutes later & 141 & 64 & 81 & 130 & 91 & 108 \\
\hline 30 & 122 & 82 & 102 & 132 & 94 & 112 \\
\hline 45 & 111 & 67 & 90 & 118 & 80 & 98 \\
\hline 60 & 119 & 77 & 93 & 124 & 88 & 104 \\
\hline 75 & 104 & 65 & 78 & 115 & 79 & 93 \\
\hline Mean & 124.6 & 74.3 & 93.50 & 123.5 & 85.66 & 102.83 \\
\hline SE & 7.33 & 4.43 & 5.86 & 2.70 & 2.53 & 2.79 \\
\hline
\end{tabular}

This study compared the efficiency of invasive and non-invasive methods of blood pressure monitoring in large animals. According to Glen (1970), the NIBP cuff placement over the tail was found to be the most effective for the measurement of non-invasive blood pressure in cattle. Our findings of non-significant difference between NIBP and IBP validates the use of NIBP in farm settings as IBP requires experienced technicians. The findings are consistent with studies conducted in small animals which show that NIBP and IBP have minimal variations (Olsen et al. 2016). The comparative findings

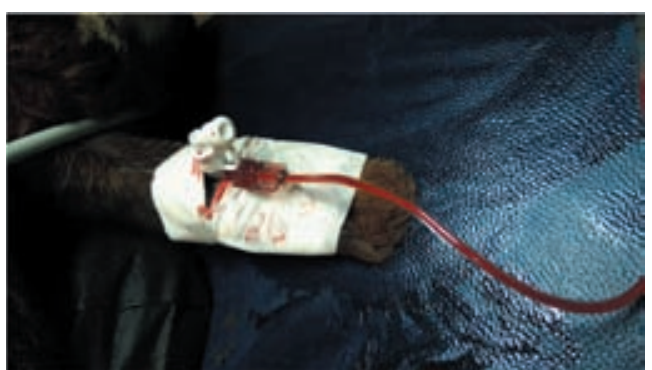

Fig. 1: Ear cannulation for IBP measurement

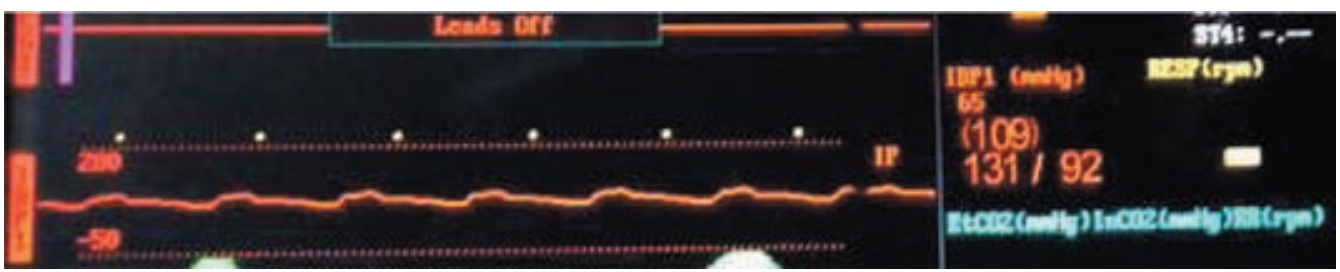

Fig. 2: IBP reading from the present study were in accordance with those reported by Nout et al. (2002) in foals. But it is in contradiction to the findings by Aarnes et al. (2014) where he concluded from his study on 38 cattle that NIBP is not an efficient alternative to IBP and this could be attributed to the tight fit of NIBP cuff around the tail used for the present study.

Blood pressure measurement is crucial for monitoring in animals. Invasive blood pressure monitoring is the gold standard for monitoring blood pressure but lack of expert technicians and equipment can hinder it's usage in the field conditions. Non-invasive blood pressure measurement can be taken as an alternative to invasive blood pressure measurement and can be utilised to monitor changes in a healthy animal undergoing surgery. It should be noted that NIBP is a reliable alternative which do not differ significantly from IBP and could be used for routine practice. 


\section{References}

Aarnes, T.K., Hubbell, J.A., Lerche, P. and Bednarski, R.M., 2014. Comparison of invasive and oscillometric blood pressure measurement techniques in anesthetized sheep, goats, and cattle. Vet. Anaesth. Analg., 41(2), pp.174-185.

Afshar, F.S., Baniadam, A. and Marashipour, S.P.2005. Effect of xylazine-ketamine on arterial blood pressure, arterial blood $\mathrm{pH}$, blood gases, rectal temperature, heart and respiratory rates in goats. BulletinVeterinary Institute in Pulawy. 49(4): 481.

Glen, J.B. 1970. Indirect blood pressure measurement in anaesthetised animals. Proceedings of the Association of Veterinary Anaesthetists. 1(1): 25-37.

Nout, Y.S., Corley, K.T., Donaldson, L.L. and Furr, M.O., 2002. Indirect oscillometric and directblood pressure measurements in anesthetized and conscious neonatal foals. J. Vet. Emerg. Crit. Car. 12(2), pp.75-80.

Olsen, E., Pedersen, T.L.S., Robinson, R. and Haubro Andersen, P., 2016. Accuracy and precision of oscillometric blood pressure in standing conscious horses. J. Vet. Emerg. Crit. Car. 26(1), pp.85-92. 